\title{
PREMATURE SENESCENCE LEAF 50 Promotes Heat Stress Tolerance in Rice (Oryza sativa
}

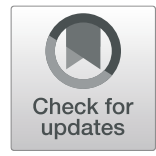
L.)

Yan He, Xiaobo Zhang, Yongfeng Shi, Xia Xu, Liangjian Li and Jian-Li Wu* (D)

\begin{abstract}
Background: Heat stress is a major environmental factor that could induce premature leaf senescence in plants. So far, a few rice premature senescent leaf mutants have been reported to involve in heat tolerance.

Findings: We identified a premature senescence leaf 50 (ps/50) mutant that exhibited a higher heat susceptibility with decreased survival rate, over-accumulated hydrogen peroxide $\left(\mathrm{H}_{2} \mathrm{O}_{2}\right)$ content and increased cell death under heat stress compared with the wild-type. The causal gene PREMATURE SENESCENCE LEAF 50 (PSL50) was isolated by using initial map-based resequencing (IMBR) approach, and we found that PSL50 promoted heat tolerance probably by acting as a modulator of $\mathrm{H}_{2} \mathrm{O}_{2}$ signaling in response to heat stress in rice (Oryza sativa L.).
\end{abstract}

Conclusions: PSL5O negatively regulates heat-induced premature leaf senescence in rice.

Keywords: Rice, Senescence, IMBR, Heat tolerance, Hydrogen peroxide

\section{Findings}

In plants, premature leaf senescence is one of the major symptoms resulting from heat stress. During heatinduced senescence, leaf cells undergo a series of cellular changes including reactive oxygen species (ROS) accumulation, photosynthetic apparatus impairment and cell death (Cui et al. 2020; Ivanov et al. 2017; Lee et al. 2014). Accordingly, plants have developed complex biochemical regulatory mechanisms to response and adapt to heat stress. For example, Arabidopsis HEAT SHOCK PROTEINS 90 (HSP90) controls the initiation of stomatal cell lineage coupled with stomatal development to adapt to heat-stress by phosphorylating MITOGENACTIVATED PROTEIN KINASEs (MPK3 and MPK6) cascades (Samakovli et al. 2020). In rice high temperature susceptibility (hts) semi-rolled leaf mutant, abscisic acid acts as a negative regulator of heat stress by mediating energy homeostasis ( $\mathrm{Li}$ et al. 2020). The plant pectin methylesterases modulate cell wall porosity and

\footnotetext{
*Correspondence: beishangd@163.com

State Key Laboratory of Rice Biology, China National Rice Research Institute, Hangzhou 310006, China
}

\section{Springer Open}

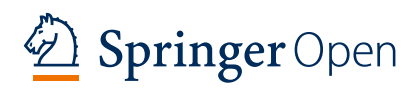

have been shown to exhibit structural variation in heat stress response (Wu et al. 2018). However, little is known about the underlying genetic and molecular mechanisms of the connection between leaf premature senescence and heat stress.

We previously characterized physio-biochemically an ethyl methane sulfonate (EMS) induced Zhongjian 100 (wild type, WT) mutant, premature senescence leaf 50 (psl50), which displayed severe premature senescent phenotype at the grain-filling stage (Fig. 1a) (He et al. 2018).

To rapidly isolate the causal gene PSL50 responsible for the premature senescent phenotype, we designed an initial map-based resequencing (IMBR) strategy to locate the candidate gene by combining initial mapping and whole-genome resequencing (Fig. 1b). To perform IMBR, PSL50 was firstly mapped to a large region covering several megabit nucleotides after the initial mapping using a small $F_{2}$ population. Secondly, psl50 and three randomly chosen mutants $(M 1, M 2$ and $M 3)$ from the same mutant bank were sampled for whole-genome resequencing. Lastly, the sequences of the target initial

(c) The Author(s). 2021, corrected publication 2021. Open Access This article is licensed under a Creative Commons Attribution 4.0 International License, which permits use, sharing, adaptation, distribution and reproduction in any medium or format, as long as you give appropriate credit to the original author(s) and the source, provide a link to the Creative Commons licence, and indicate if changes were made. The images or other third party material in this article are included in the article's Creative Commons licence, unless indicated otherwise in a credit line to the material. If material is not included in the article's Creative Commons licence and your intended use is not permitted by statutory regulation or exceeds the permitted use, you will need to obtain permission directly from the copyright holder. To view a copy of this licence, visit http://creativecommons.org/ licenses/by/4.0\%. 


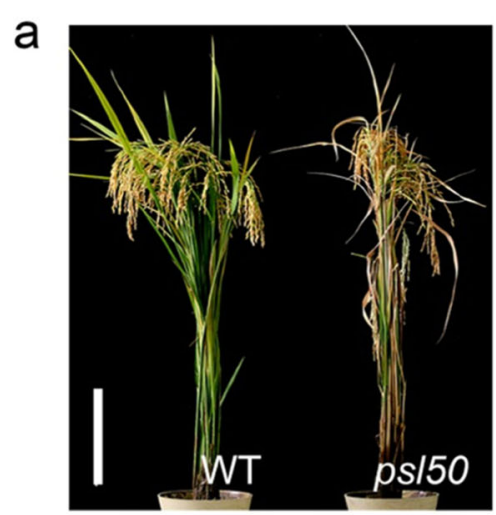

C

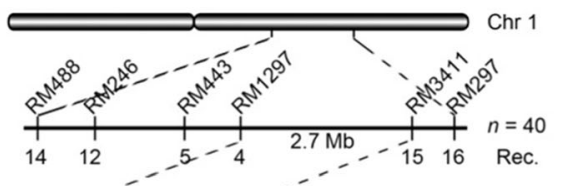

b

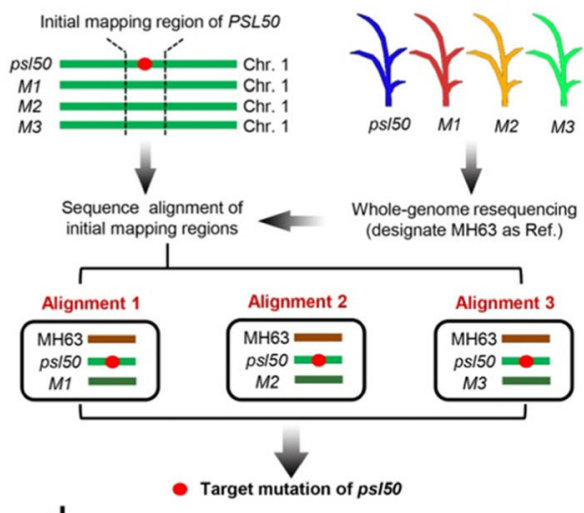

d

Kitaake $\frac{\text { Target }}{n}$ Cas9-2 GGTGTCGGCGCCTGTT-CTTCTCC Cas9-5 GGTGTCGGCGCCTGTT - -TTCTCC Cas9-12 GGTGTCGGCGCCTGTTCCtTTCTCC

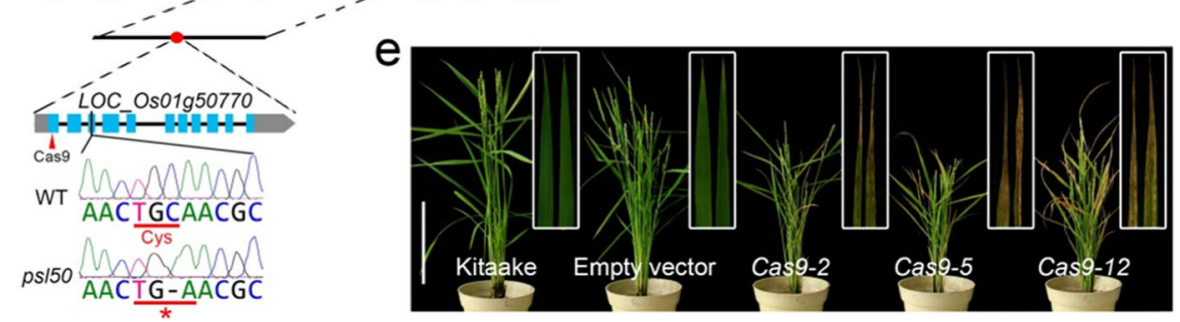

Fig. 1 Identification of PSL50 by IMBR strategy. a Phenotype of WT and ps/50 at the mature stage. Scale bar $=20 \mathrm{~cm}$. $\mathbf{b}$ Identification of target mutation of psI50 by IMBR strategy. Red dot indicates the causative mutation responsible for the ps/50 phenotype. c Initial mapping of PSL50 and verification of target mutation in PSL50. d Deletion and insertion mutation at the target site of 1st exon in three representative knockout lines generated by CRISPR/Cas9 in 'Kitaake' background. The Cas9-2, Cas9-5 and Cas9-12 lines are homozygous mutants carrying a 1-bp deletion, a 2bp deletion and a 1-bp insertion on both homochromosomes, respectively. e Phenotype of three representative $T_{0}$ knockout lines at the heading stage. Insets display magnified views of flag leaves. Empty vector represents transgenic Kitaake plant transformed with CRISPR/Cas9 empty vector. Scale bar $=20 \mathrm{~cm}$

mapping region from the four lines were aligned and compared with the reference genome of indica rice Minghui 63 (MH63, http://rice.hzau.edu.cn/cgi-bin/gb2/ gbrowse/MH63RS2/) (Zhang et al. 2016) to detect SNP and/or InDel variations. It is not necessary to sequence WT because the sequences of four mutant lines can be used as control or biological replicates to lower/eliminate sequencing errors.

As a proof of concept, a total of 178 polymorphic simple sequence repeat (SSR) markers evenly distributed over 12 chromosomes between parental line psl50 and japonica line 80A90YR72 were used for linkage analysis of two bulked segregant analysis (BSA) DNA pools derived from the wild-type and mutant type $\mathrm{F}_{2}$ progenies from the cross psl50/80A90YR72. The results showed that three SSR markers RM297, RM443 and RM488 were co-segregated with the mutation. Further mapping indicated that PSL5O localized to a $2.7-\mathrm{Mb}$ genomic region between RM3411 and RM1297 at the long arm of chromosome 1 by using 40 psl50-type $\mathrm{F}_{2}$ individuals derived from the cross psl50/80A90YR72 (Fig. 1c). Sequence alignments of the $2.7-\mathrm{Mb}$ region showed that there were 155, 162 and $158 \mathrm{SNPs} / \mathrm{InDels}$ between psl50/M1, psl50/M2 and psl50/M3, respectively (Additional file 2: Table S1-S3). Obviously, most SNPs/ InDels presented two types of genotype between psl50 and the other three mutants, we cannot consider them as the true SNPs/InDels. Only the site(s) showing a single genotype at all allele depth was considered as true SNPs/InDels. As shown in Table S1, S2, S3, only the position at $28,281,174$ within the third exon of LOC_Os01g50770 exhibited the nucleotide substitution from GC to $\mathrm{G}$ with single genotype in allele depth among all the sequence alignments between psl50 (G/G with 0,24 allele depth) and the other three mutants (GC/GC with 10,0 allele depth for $M 1,14,0$ for $M 2$ and 18,0 for $M 3$, respectively). These results revealed that the variation from GC to $\mathrm{G}$ at the position $28,281,174$ was a true 1-bp deletion mutation in LOC_Os01g50770 (Table 1; Fig. 1c). 
Table 1 Nucleotide comparison of target mutation site between ps/50 and the other three mutants

\begin{tabular}{llllll}
\hline Material & Position & Genotype & Mutant depth & Mutant allele depth & Mutation type \\
\hline ps/50 & $28,281,174$ & G & 10 & 10,0 & GC to G (frameshift) \\
M1 & $28,281,174$ & GC & 14 & 14,0 & GC (wild-type) \\
M2 & $28,281,174$ & GC & 18 & 18,0 & GC (wild-type) \\
M3 & $28,281,174$ & GC & 24 & 24,0 & GC (wild-type) \\
MH63 & $28,281,174$ & GC & & & GC \\
\hline
\end{tabular}

We further performed sequencing on polymerase chain reaction (PCR) products to confirm the 1-bp deletion mutation which leads to a premature stop codon (Fig. 1c; Additional file 1: Figure S1a). LOC_Os01g50770 is predicted to encode a clathrin-associated adaptor protein complex 1 medium subunit $\mu 1$ (AP1M1). The mutation type $L O C$ Os01g50770 is predicted to encode a truncated protein ( $\triangle$ PSL50) lacking the AP-1 complex subunit $\mu \mathrm{N}$-terminal domain, and the functional domain deletion could be observed visually by modeling the three-dimensional protein structures of PSL50 and $\triangle$ PSL50 (Additional file 1: Figure S1b, c). To quickly demonstrate whether the mutation of LOC_Os01g50770 was responsible for premature leaf senescence in psl50, we transformed a CRISPR/Cas9 construct targeting the first exon of $L O C \_O s 01 g 50770$ into a japonica rice variety Kitaake (Fig. 1d). Expectedly, all 13 knockout homozygous lines of $\mathrm{T}_{0}$ transgenic plants showed premature senescence leaf phenotype similar to psl50 (Fig. 1e). These results confirmed that LOC_Os01g50770 was PSL50, and the mutation of PSL50 caused the premature senescence leaf phenotype in psl50. Furthermore, we a

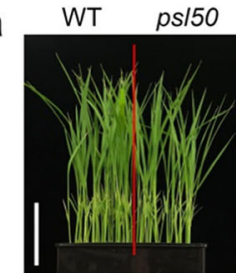

$26^{\circ} \mathrm{C}$

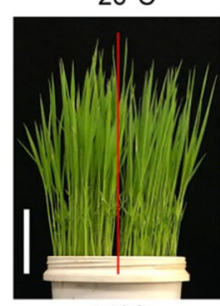

$26^{\circ} \mathrm{C}$

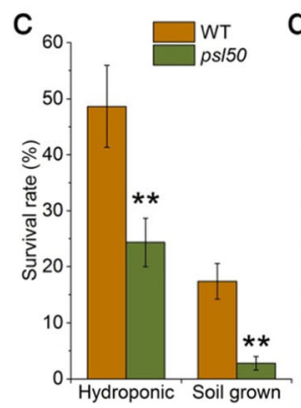

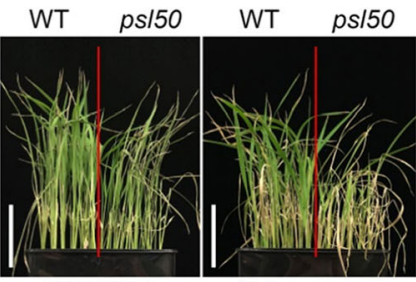

$45^{\circ} \mathrm{C} 50 \mathrm{~h}$

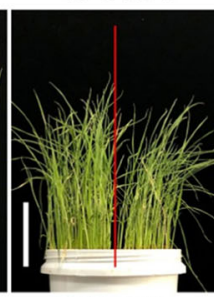

$45^{\circ} \mathrm{C} 40 \mathrm{~h}$

$7 \mathrm{~d}$ recovery

14 d recovery

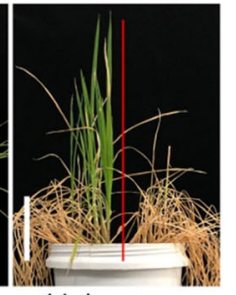

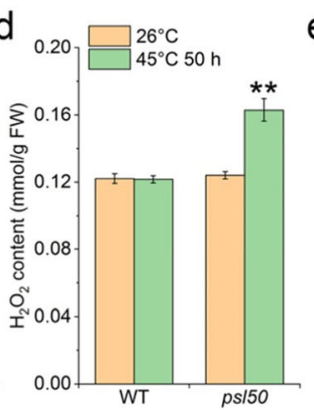
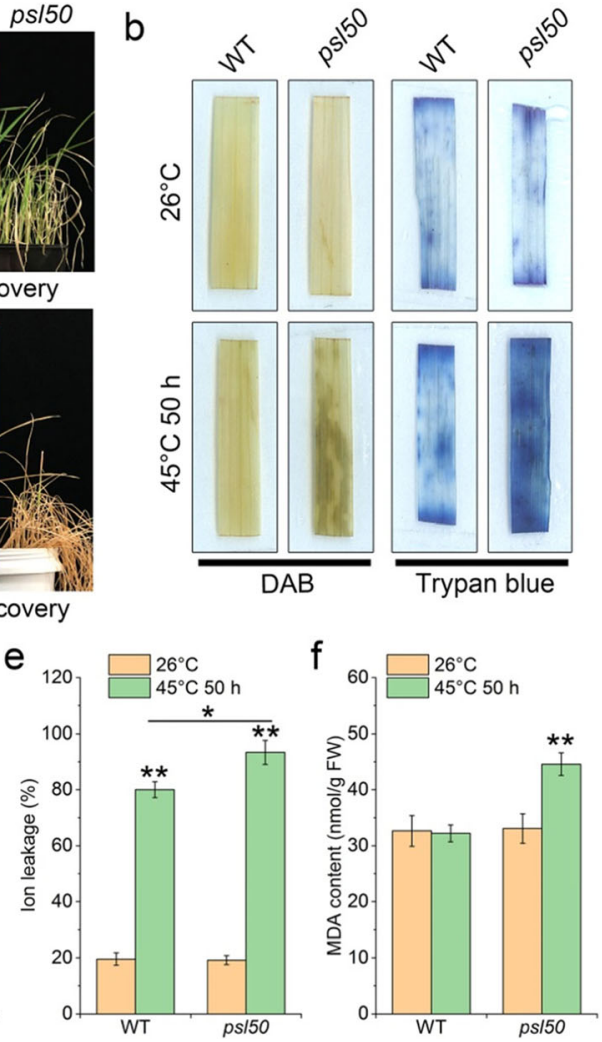

Fig. 2 Effects of heat stress on ps/50 and WT at the seedling stage. a Phenotypes of WT and ps/50 seedlings under heat stress. Seedlings were hydroponically (upper row) or soil grown (lower row) at $26^{\circ} \mathrm{C}$ for $12 \mathrm{~d}$ and then treated at $45^{\circ} \mathrm{C}$ for $50 \mathrm{~h}$ or $40 \mathrm{~h}$ followed a recovery at $26^{\circ} \mathrm{C}$. Scale bars $=5 \mathrm{~cm}$. $\mathbf{b}$ DAB staining for $\mathrm{H}_{2} \mathrm{O}_{2}$ accumulation detection and trypan blue staining for cell death detection in the top 2nd leaves of hydroponical seedlings before and after heat treatment. c Survival rate of hydroponic WT and ps/50 seedlings shown in a. d-f $\mathrm{H}_{2} \mathrm{O}_{2}$ content, ion leakage rate and MDA content in hydroponic WT and ps/50 seedlings before and after heat treatment. Data are means \pm SD $(n=3)$. Asterisks indicate significant difference by Student's $t$ test ${ }^{* *} P<0.01$ and $\left.{ }^{*} P<0.05\right)$ 
also successfully identified other true mutations in the three control mutants (data not shown), indicating the feasibility of IMBR strategy in rapid gene isolation.

Many senescence-associated mutants have been identified in various plant species (Liang et al. 2014; Zhao et al. 2016; Shim et al. 2019), while most of the studies focused on the interpretation of senescence-related genetic mechanisms. To explore the association between environmental factors and premature leaf senescence, we carried out a heat treatment on psl50 at the seedling stage. Under normal growth conditions at $26^{\circ} \mathrm{C}$, no any overt abnormalities or defects were observed in psl50 compared with WT. However, when 12-day-old seedlings were subjected to heat treatment at $45^{\circ} \mathrm{C}$ under hydroponics and soil growth conditions, psl50 was more susceptible to heat stress and showed lower survival rate than those of WT (Fig. 2a, c). Hydrogen peroxide $\left(\mathrm{H}_{2} \mathrm{O}_{2}\right)$ over-accumulation is shown to induce plant cell death (He et al. 2020; Sathe et al. 2019). We hence detected $\mathrm{H}_{2} \mathrm{O}_{2}$ accumulation and cell death of $p s l 50$ seedlings with and without heat treatment by using 3,3'diaminobenzidine $(\mathrm{DAB})$ and trypan blue staining. The results showed that psl50 had similar level of $\mathrm{H}_{2} \mathrm{O}_{2}$ accumulation and cell death before heat treatment at $26^{\circ} \mathrm{C}$, whereas psl50 had higher levels of $\mathrm{H}_{2} \mathrm{O}_{2}$ accumulation and cell death after heat treatment at $45^{\circ} \mathrm{C}$ compared with WT (Fig. 2b, d). Although ion leakage rate was dramatically increased both in WT and psl50 after heat treatment, psl50 showed significantly increased ion leakage rate compared to WT (Fig. 2e). As another indicator of cell membrane damage, the malonaldehyde (MDA) content was similar between psl50 and WT before heat treatment, while obviously increased in psl50 after heat treatment (Fig. 2f). These results indicated that PSL50 could positively contribute to heat tolerance, while dysfunction of PSL5O in psl50 resulted in higher heat stress susceptibility associated with cell membrane damage and $\mathrm{H}_{2} \mathrm{O}_{2}$-induced cell death. In addition, the $\mathrm{H}_{2} \mathrm{O}_{2}$ content was similar in green leaves of WT and psl50, while prominently increased in premature senescent leaves of psl50 (Additional file 1: Figure S2). Considering the rapid premature leaf senescence occurred in psl50 at the grain-filling stage which often accompanied with higher temperatures in natural conditions, we speculated that high temperatures might act as an inducer for premature leaf senescence in psl50, involving $\mathrm{H}_{2} \mathrm{O}_{2}$ signaling response pathway.

PSL50 is likely allelic to SPOTTED LEAF 28 (SPL28) in rice, which is involved in the regulation of vesicular trafficking, and the dysfunction of SPL28 results in the formation of hypersensitive response (HR)-like lesions, leading to the initiation of leaf senescence (Qiao et al. 2010). To detect the subcellular location of PSL50, we fused the green fluorescent protein (GFP) to the C- terminus of PSL50 driven by the CaMV35S promoter to create the PSL50::GFP fusion protein. The PSL50::GFP fluorescent signals were co-localized with NST1:: mCherry, a Golgi-tagged marker (Zhang et al. 2011), indicating that PSL50 localized to the Golgi apparatus (Fig. 3a), and this result was consistent with the subcellular localization of SPL28 in onion epidermal cells (Qiao et al. 2010). The expression of PSL50 was detectable in all different rice organs at different developmental stages, and its expression increased gradually from the top to the base of a fully expanded flag leaf (Fig. 3b, c). In addition, we examined PSL50 expression in different leaves at the mature stage, and found that PSL5O transcripts were higher in younger, greener leaves than those of older and senescing leaves (Additional file 1: Figure S3). The results suggested that PSL50 was widely expressed and acted as a negative regulator for natural rice leaf senescence. To explore the roles of PSL5O in heat tolerance, we further investigated the kinetic mRNA level alterations of PSL50 in WT and psl50 under heat stress conditions. In WT, PSL50 mRNA levels decreased by 0.4 -fold after $2 \mathrm{~h}$ heat treatment, and increased rapidly by 2.4 -fold after $4 \mathrm{~h}$ heat treatment, whereas in psl50, a similar variation trend of PSL50 mRNA levels emerged after $6 \mathrm{~h}$ heat treatment (Fig. $3 \mathrm{~d}$ ). The results indicated that PSL50 transcription was induced by heat stress and the delayed expression of non-functional PSL50 in psl50 may be resulted from the loss of PSL50 function.

We also detected the transcripts of ROS-scavenging system associated genes, including ascorbate peroxidase (APX) genes OsAPX1and OsAPX2 (Bonifacio et al. 2016), catalase genes OsCATA, OsCATB and OsCATC (Lin et al. 2012; Ye et al. 2011), alternative oxidase (AOX) genes OsAOX1a, OsAOX1b and OsAOX1c (Fujii and Toriyama 2008; Saika et al. 2002), and superoxide dismutase (SOD) genes $\mathrm{Cu} / \mathrm{Zn}-\mathrm{SOD}, \mathrm{Mn}-\mathrm{SOD}$ and $\mathrm{Fe}$ $S O D$ (Wang et al. 2016; Guan et al. 2017). APX catalyzes the reduction of $\mathrm{H}_{2} \mathrm{O}_{2}$ into water, and OsAPX1 was down-regulated in psl50 under normal growth and heat stress conditions (Fig. 3e). Under normal growth conditions, the reduced level of OsAPX1 and normal level of OsAPX2 in psl50 might be enough to maintain the balance of $\mathrm{H}_{2} \mathrm{O}_{2}$ production and scavenging. Whereas in case of heat stress conditions, the ROS burst was highly induced and the up-regulation of OsAPX2 in psl50 might partially compensate for the down-regulated OsAPX1(Figs. 2d, 3e). Under normal growth conditions, OsCATA was up-regulated in psl50 while the expressions of OsCATB/C were similar to WT, in contrast, the expression of $O s C A T B$ was highly down-regulated while the expression of OsCATC was apparently up-regulated in psl50 compared with WT under heat stress (Fig. 3e). We speculated that a similar compensation mechanism 

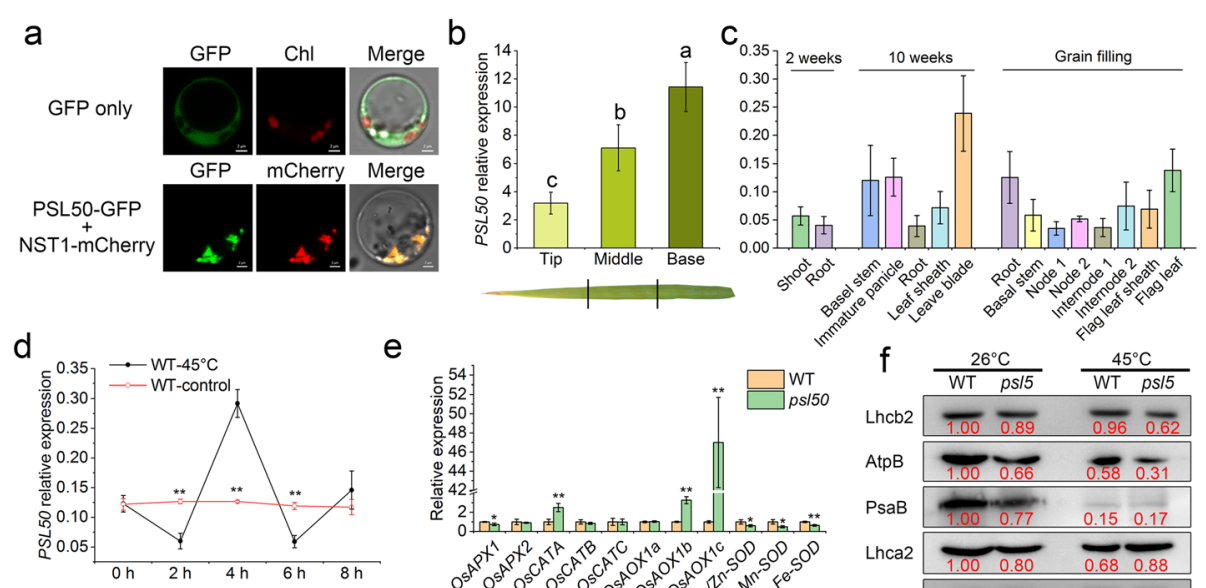

e
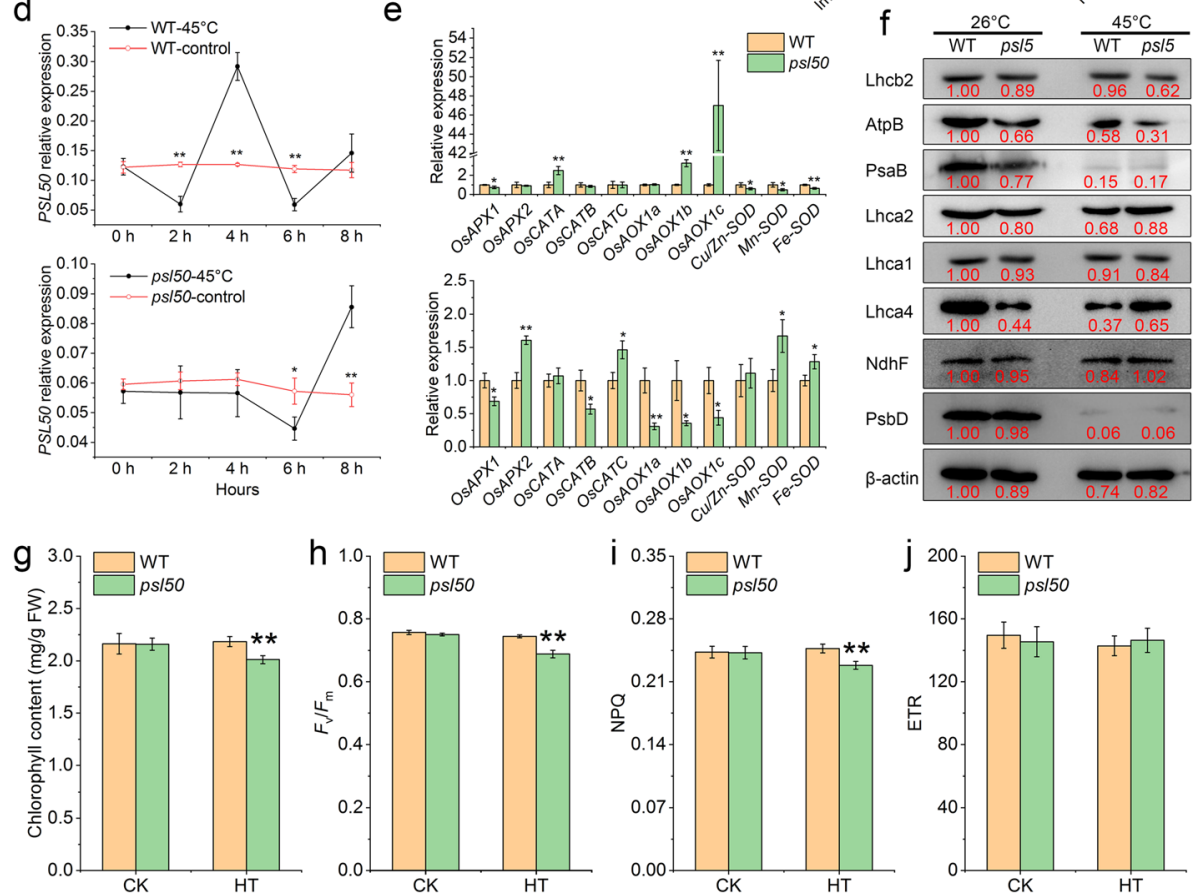

Fig. 3 Subcellular localization and expression analysis of PSL50. a GFP signals in rice protoplasts. NST1-mCherry was used as a rice protoplast Golgi-tagged marker. b PSL50 expression in different parts of a flag leaf. Different letters indicate significant differences according to one-way ANOVA and Duncan's test $(P<0.05)$. Data are mean \pm SD $(n=3)$. c Relative expression levels of PSL50 in various organs at different growth stages. Data are presented as mean \pm SD $(n=3)$. $\mathbf{d}$ Expression analysis of PSL50 in hydroponic WT and ps/50 seedlings under heat stress conditions. Data are mean $\pm S D(n=3)$. e Expression analysis of ROS scavenging system-related genes in hydroponic WT and ps/50 seedlings at $26^{\circ} \mathrm{C}$ (upper) and $45^{\circ} \mathrm{C}$ (lower) for $12 \mathrm{~h}$. Data are mean \pm SD $(n=3)$. Rice UBIQUITIN (LOC_Os03g13170) was used as an internal control. $\mathbf{f}$ Levels of thylakoid membrane proteins detected in total proteins from top second leaves of $12 \mathrm{~d} \mathrm{WT}$ and ps 150 hydroponic seedlings at $26^{\circ} \mathrm{C}$ and $45^{\circ} \mathrm{C}$ for $50 \mathrm{~h}$. Image J was used for the quantification of immunoblot results and these experiments were repeated at least twice with similar results. $\mathbf{g}$ Leaf chlorophyll content of hydroponic WT and ps/50 seedlings before and after heat treatment. Data are means \pm SD $(n=3)$. $\mathbf{h}-\mathbf{j}$ Changes of photochemical efficiency of PSII $\left(F_{\mathrm{v}} / F_{\mathrm{m}}\right)$, non-photochemical fluorescence quenching (NPQ) and relative PSIl electron transport rate (ETR) in WT and ps/50 under heat treatment. The data for heat treatment in $\mathbf{g}$-h were collected after a $7-\mathbf{d}$ recovery at $26^{\circ} \mathrm{C}$. Seedlings were hydroponically grown at $26^{\circ} \mathrm{C}$ for $12 \mathrm{~d}$ and then treated at $45^{\circ} \mathrm{C}$ for $50 \mathrm{~h}$ following a $7-\mathrm{d}$ recovery at $26^{\circ} \mathrm{C}$. CK, normal growth condition at $26^{\circ} \mathrm{C} ; \mathrm{HT}$, heat treatment at $45^{\circ} \mathrm{C}$ followed by recovery at $26^{\circ} \mathrm{C}$ for $7 \mathrm{~d}$. Data are means $\pm S D(n=5)$. Asterisks indicate significant difference by Student's $t$ test $\left(* * P<0.01\right.$ and $\left.{ }^{*} P<0.05\right)$

might occur among CAT isozyme genes (Fig. 3e). Compared to the normal growth conditions at $26^{\circ} \mathrm{C}$, we also found that heat stress restrained the expression of $O s A O X 1 a$, OsAOX1b and OsAOX1c, while improved the expression of $\mathrm{Mn}$-SOD and $\mathrm{Fe}-\mathrm{SOD}$ in psl5O (Fig. 3e). AOX is a mitochondrial respiratory oxidase playing important roles in intracellular oxygen molecule scavenging while SOD catalyzes the superoxide anion to $\mathrm{H}_{2} \mathrm{O}_{2}$ (Baurain et al. 2003; Asada 2006). Therefore, the increased transcriptional level of SOD genes and decreased transcriptional level of AOX genes would facilitate the
ROS accumulation in psl50 under heat stress, which likely confers the higher heat susceptibility of psl50.

In plants, ROS are mainly produced during the light reaction of photosystem II (PSII) and PSI complex at thylakoids, and PSII is the most thermolabile photosynthetic complex (Asada 2006; Chen et al. 2017). Thus, immunoblot was performed to test whether the major components of thylakoid membrane complexes were impaired under heat stress. As the core subunits of PSII and PSI complexes, PsaB and PsbD were dramatically decreased in both WT and psl50 after $45^{\circ} \mathrm{C}$ heat 
treatment (Fig. 3f), indicating that heat stress commonly causes severe thermal damage not only to PSII but also PSI. Unlike the decreased levels of LHCII type II chlorophyll $a / b$-binding protein Lhcb2 and ATP synthase $\beta$ subunit (AtpB) in psl50 after heat treatment, the accumulations of light-harvesting antenna of PSI (LHCI) chlorophyll $a / b$-binding proteins Lhcal, was not obviously affected by heat treatment, similarly, the retained Lhca2 and Lhca4 protein levels in psl50 were near to the WT levels (at $26^{\circ} \mathrm{C}$ ) after heat treatment (Fig. 3f). Compared with WT, the non-photochemical quenching (NPQ) value of psl50 was lower under heat treatment, suggesting that heat stress impaired the NPQ process for heat dissipation which serves to prevent damage to PSII, and the decreased PSII antenna Lhcb2 protein level in psl50 after heat treatment might associate with the weaker NPQ capacity of psl50 (Fig. 3f, i). Meanwhile, comparable $\mathrm{NAD}(\mathrm{P}) \mathrm{H}$ dehydrogenase subunit 5 (NdhF) levels and relative PSII electron transport rate (ETR) in WT and psl50 indicated that electron transfer was normal under heat treatment (Fig. 3f, j). To further investigate the harmful effects of PSL50 disruption on the photosynthetic capacity, we then measured the maximum quantum efficiency of PSII photochemistry $(F \mathrm{~V} /$ $F \mathrm{~m})$. In agreement with the psl50 heat-sensitive phenotype, the values of $F \mathrm{v} / F \mathrm{~m}$ and chlorophyll content were also lower in psl50 than those of WT under heat stress (Fig. 3g, h). In addition, we determined whether light intensity affects the heat susceptibility of psl50. Intriguingly, it was showed that the heat tolerance of both WT and psl50 plants was obviously facilitated by high light intensity (HL) (Additional file 1: Figure S4a). However, under heat treatment (HT) with normal light intensity (NL), the survival rate of psl50 was significantly lower than WT after a 7-d recovery, and the $F \mathrm{v} / F \mathrm{~m}$ was even not detectable in psl50 (Additional file 1: Figure S4b, c). These results suggested that the higher heat susceptibility of psl50 may be the consequence of impaired photosynthesis under NL and HT conditions. While under HL and HT conditions, the photosynthetic potential productivity of plants was motivated by HL, which ultimately improved the heat tolerance of both WT and psl50 and even eliminated the heat tolerance disparity between WT and psl50. Plants frequently encounter a combination of two or multiple abiotic stresses in nature at a time. Though combined abiotic stresses generally have greater negative effects on plants than that of single type abiotic stress, previous studies also have shown that some abiotic stresses could actually enhance plant tolerance to another abiotic stress (Choudhury et al. 2017; Miller et al. 2010), and plants are able to integrate two different stress-specific systemic signals (induced by light or/and heat) to improve its acclimation in coordinating different transcriptional responses, such as ROS- and salicylic acid (SA)-transcript variations (Zandalinas et al. 2020). In summary, these data demonstrated that PSL50 is essential for the heat tolerance regulation of rice plants by maintaining the stability of photosynthetic system under heat stress, and the high light intensity can enhance the heat tolerance of both WT and psl50.

Taken together, we successfully identified and isolated rice PSL50 by using the IMBR strategy. Furthermore, we found that PSL50 played important roles both in rice premature leaf senescence and heat stress response, involving in the regulations of $\mathrm{H}_{2} \mathrm{O}_{2}$ accumulation and photosynthetic adaption. This study would facilitate studies on functions of PSL50 in heat stress-induced premature leaf senescence.

\section{Supplementary Information}

The online version contains supplementary material available at https://doi. org/10.1186/s12284-021-00493-w.

Additional file 1: Figure S1. Mutation analysis of PSL50. Figure S2. Leaf phenotypes and $\mathrm{H}_{2} \mathrm{O}_{2}$ content of WT and ps/50 at $40 \mathrm{~d}$ after transplanting. Figure S3. PSL50 expression in different leaves at the mature stage. Figure S4. Effects of light intensity on WT and ps/50 seedlings under heat stress.

Additional file 2: Table S1. INDEL and SNP between ps/50 and mutant 1. Table S2. INDEL and SNP between ps/50 and mutant 2. Table S3. INDEL and SNP between ps/50 and mutant 3. Table S4. List of primers used in this study.

Additional file 3. Materials and Methods (Ma et al. 2015; Yu et al. 2020).

\section{Authors' Contributions}

$\mathrm{YH}$ and JW conceived the experiments. YH, YS, XX and LL performed most of the experiments. $X Z$ carried out vector construction. $Y H$ analyzed the data and drafted the manuscript. JW supervised the study and revised the manuscript. All authors read and approved the final manuscript.

\section{Funding}

This research was funded by the Central Public-interest Scientific Institution Basal Research Fund of China National Rice Research Institute (2017RG002-2).

Availability of Data and Materials

All data supporting the conclusions of this article are provided within the article (and its additional files).

\section{Declarations}

Ethics Approval and Consent to Participate Not applicable.

Consent for Publication

Not applicable.

Competing Interests

The authors declare that they have no competing interests.

Received: 19 November 2020 Accepted: 13 May 2021

Published online: 12 June 2021

\section{References}

Asada K (2006) Production and scavenging of reactive oxygen species in chloroplasts and their functions. Plant Physiol 141(2):391-396. https://doi. org/10.1104/pp.106.082040

Baurain D, Dinant M, Coosemans N, Matagne RF (2003) Regulation of the alternative oxidase Aoxl gene in Chlamydomonas reinhardtii. Role of the 
nitrogen source on the expression of a reporter gene under the control of the Aox1 promoter. Plant Physiol 131(3):1418-1430. https://doi.org/10.1104/ pp.013409

Bonifacio A, Carvalho FEL, Martins MO, Lima Neto MC, Cunha JR, Ribeiro CW, Margis-Pinheiro M, Silveira JAG (2016) Silenced rice in both cytosolic ascorbate peroxidases displays pre-acclimation to cope with oxidative stress induced by 3-aminotriazole-inhibited catalase. J Plant Physiol 201:17-27. https://doi.org/10.1016/j.jplph.2016.06.015

Chen ST, He NY, Chen JH, Guo FQ (2017) Identification of core subunits of photosystem II as action sites of HSP21, which is activated by the GUN5mediated retrograde pathway in Arabidopsis. Plant J 89(6):1106-1118. https://doi.org/10.1111/tpj.13447

Choudhury FK, Rivero RM, Blumwald E, Mittler R (2017) Reactive oxygen species, abiotic stress and stress combination. Plant J 90(5):856-867. https://doi.org/1 $0.1111 /$ tpj.13299

Cui YM, Lu S, Li Z, Chen JW, Hu P, Zhu TQ, Wang X, Jin M, Wang XX, Li LQ, Huang SY, Zou BH, Hua J (2020) CYCLIC NUCLEOTIDE-GATED ION CHANNELS 14 and 16 promote tolerance to heat and chilling in rice. Plant Physiol 183(4):1794-1808. https://doi.org/10.1104/pp.20.00591

Fujii S, Toriyama K (2008) DCW11, down-regulated gene 11 in CW-type cytoplasmic male sterile rice, encoding mitochondrial protein phosphatase 2c is related to cytoplasmic male sterility. Plant Cell Physio 49(4):633-640. https://doi.org/10.1093/pcp/pcn036

Guan QJ, Liao X, He ML, Li XF, Wang ZY, Ma HY, Yu S, Liu SK (2017) Tolerance analysis of chloroplast OsCu/Zn-SOD overexpressing rice under $\mathrm{NaCl}$ and $\mathrm{NaHCO}_{3}$ stress. PLoS One 12(10):e0186052. https://doi.org/10.1371/journal. pone.0186052

He Y, Li L, Zhang ZH, Wu JL (2018) Identification and comparative analysis of premature senescence leaf mutants in rice (Oryza sativa L). Int J Mol Sci 19(1):140. https://doi.org/10.3390/ijms19010140

He Y, Shi YF, Zhang X, Xu X, Wang HM, Li LJ, Zhang ZH, Shang HH, Wang ZH, Wu JL (2020) The OsABCI7 transporter interacts with OsHCF222 to stabilize the thylakoid membrane in rice. Plant Physiol 184(1):283-299. https://doi. org/10.1104/pp.20.00445

Ivanov AG, Velitchkova MY, Allakhverdiev SI, Huner NPA (2017) Heat stressinduced effects of photosystem I: an overview of structural and functional responses. Photosynth Res 133(1-3):17-30. https://doi.org/10.1007/s11120-01 7-0383-x

Lee S, Lee HJ, Huh SU, Paek KH, Ha JH, Park CM (2014) The Arabidopsis NAC transcription factor NTL4 participates in a positive feedback loop that induces programmed cell death under heat stress conditions. Plant Sci 227: 76-83. https://doi.org/10.1016/j.plantsci.2014.07.003

Li GY, Zhang CX, Zhang GH, Fu WM, Feng BH, Chen TT, Peng SB, Tao LX, Fu GF (2020) Abscisic acid negatively modulates heat tolerance in rolled leaf rice by increasing leaf temperature and regulating energy homeostasis. Rice 13(1):18. https://doi.org/10.1186/s12284-020-00379-3

Liang CZ, Wang YQ, Zhu YN, Tang JY, Hu B, Liu LC, Ou SJ, Wu HK, Sun XH, Chu JF, Chu CC (2014) OsNAP connects abscisic acid and leaf senescence by finetuning abscisic acid biosynthesis and directly targeting senescenceassociated genes in rice. Proc Natl Acad Sci U S A 111(27):10013-10018. https://doi.org/10.1073/pnas.1321568111

Lin AH, Wang YQ, Tang JY, Xue P, Li CL, Liu LC, Hu B, Yang FQ, Loake GJ, Chu CC (2012) Nitric oxide and protein S-nitrosylation are integral to hydrogen peroxide-induced leaf cell death in rice. Plant Physiol 158(1):451-464. https:// doi.org/10.1104/pp.111.184531

Ma XL, Zhang QY, Zhu QL, Liu W, Chen Y, Qiu R, Wang B, Yang ZF, Li HY, Lin YR, Xie $Y Y$, Shen RX, Chen SF, Wang Z, Chen YL, Guo JX, Chen LT, Zhao XC, Dong ZC, Liu YG (2015) A robust CRISPR/Cas9 system for convenient, highefficiency multiplex genome editing in monocot and dicot plants. Mol Plant 8(8):1274-1284. https://doi.org/10.1016/j.molp.2015.04.007

Miller G, Suzuki N, Ciftci-Yilmaz S, Mittler R (2010) Reactive oxygen species homeostasis and signaling during drought and salinity stresses. Plant Cell Environ 33(4):453-467. https://doi.org/10.1111/j.1365-3040.2009.02041.x

Qiao YL, Jiang WZ, Lee JH, Park BS, Choi MS, Piao RH, Woo MO, Roh JH, Han LZ Paek NC, Seo HS, Koh HJ (2010) SPL28 encodes a clathrin-associated adaptor protein complex 1, medium subunit $\mu 1$ (AP1M1) and is responsible for spotted leaf and early senescence in rice (Oryza sativa). New Phytol 185(1): 258-274. https://doi.org/10.1111/j.1469-8137.2009.03047.x

Saika H, Ohtsu K, Hamanaka S, Nakazono M, Tsutsumi N, Hirai A (2002) AOX1c, a novel rice gene for alternative oxidase; comparison with rice $A O X 1 a$ and AOX1b. Genes Genet Syst 77(1):31-38. https://doi.org/10.1266/ggs.77.31
Samakovli D, Tichá T, Vavrdová T, Ovečka M, Luptovčiak I, Zapletalová V, Kuchařová A, Křenek $\mathrm{P}$, Krasylenko Y, Margaritopoulou T, Roka L, Milioni D, Komis G, Hatzopoulos P, Šamaj J (2020) YODA-HSP90 module regulates phosphorylation-dependent inactivation of SPEECHLESS to control stomatal development under acute heat stress in Arabidopsis. Mol Plant 13(4):612-633. https://doi.org/10.1016/j.molp.2020.01.001

Sathe AP, Su X, Chen Z, Chen T, Wei XJ, Tang SQ, Zhang XB, Wu JL (2019) Identification and characterization of a spotted-leaf mutant sp/40 with enhanced bacterial blight resistance in rice. Rice 12(1):68. https://doi.org/1 0.1186/s12284-019-0326-6

Shim Y, Kang K, An G, Paek NC (2019) Rice DNA-binding one zinc finger 24 (OsDOF24) delays leaf senescence in a jasmonate-mediated pathway. Plant Cell Physiol 60(9):2065-2076. https://doi.org/10.1093/pcp/pcz105

Wang FB, Liu JC, Zhou LJ, Pan G, Li ZW, Zaidi SHR, Cheng FM (2016) Senescencespecific change in ROS scavenging enzyme activities and regulation of various SOD isozymes to ROS levels in psf mutant rice leaves. Plant Physiol Biochem 109:248-261. https://doi.org/10.1016/j.plaphy.2016.10.005

Wu HC, Bulgakov VP, Jinn TL (2018) Pectin methylesterases: cell wall remodeling proteins are required for plant response to heat stress. Front Plant Sci 9:1612. https://doi.org/10.3389/fpls.2018.01612

Ye NH, Zhu GH, Liu YG, Li YX, Zhang JH (2011) ABA controls $\mathrm{H}_{2} \mathrm{O}_{2}$ accumulation through the induction of OSCATB in rice leaves under water stress. Plant Cell Physiol 52(4):689-698. https://doi.org/10.1093/pcp/pcr028

Yu PH, Jiang N, Fu WM, Zheng GJ, Li GY, Feng BH, Chen TT, Ma JY, Li HB, Tao LX, Fu GF (2020) ATP hydrolysis determines cold tolerance by regulating available energy for glutathione synthesis in rice seedling plants. Rice 13(1): 23. https://doi.org/10.1186/s12284-020-00383-7

Zandalinas SI, Fichman Y, Devireddy AR, Sengupta S, Azad RK, Mittler R (2020) Systemic signaling during abiotic stress combination in plants. Proc Natl Acad Sci U S A 117(24):13810-13820. https://doi.org/10.1073/pnas.2005077117

Zhang BC, Liu XL, Qian Q, Liu LF, Dong GJ, Xiong GY, Zeng DL, Zhou YH (2011) Golgi nucleotide sugar transporter modulates cell wall biosynthesis and plant growth in rice. Proc Natl Acad Sci U S A 108(12):5110-5115. https://doi.org/1 0.1073 /pnas.1016144108

Zhang J, Chen LL, Xing F, Kudrna DA, Yao W, Copetti D, Mu T, Li W, Song JM, Xie $W$ et al (2016) Extensive sequence divergence between the reference genomes of two elite indica rice varieties Zhenshan 97 and Minghui 63. Proc Natl Acad Sci U S A 113:5163-5171

Zhao Y, Chan ZL, Gao JH, Xing L, Cao MJ, Yu CM, Hu YL, You J, Shi HT, Zhu YF, Gong YH, Mu ZX, Wang HQ, Deng X, Wang PC, Bressan RA, Zhu J (2016) ABA receptor PYL9 promotes drought resistance and leaf senescence. Proc Natl Acad Sci U S A 113(7):1949-1954. https://doi.org/10.1073/pnas.1522840113

\section{Publisher's Note}

Springer Nature remains neutral with regard to jurisdictional claims in published maps and institutional affiliations.

\section{Submit your manuscript to a SpringerOpen ${ }^{\circ}$ journal and benefit from:}

- Convenient online submission

- Rigorous peer review

- Open access: articles freely available online

- High visibility within the field

- Retaining the copyright to your article

Submit your next manuscript at $\boldsymbol{\nabla}$ springeropen.com 